\title{
Branded Media Text as Communicative-integration Model of Interaction with Audience
}

\author{
Svetlana Urazova ${ }^{1}$, Irina Volkova $^{2, *}$, Ekaterina Baranova ${ }^{3}$ Andrey Druzhinin ${ }^{1}$, and Anastasia Ulyura $^{2}$ \\ ${ }^{1}$ Academy of Media Industry, Research Sector, 127521, Oktyabrskaya str., 105-2, Moscow, Russian Federation. \\ ${ }^{2}$ RUDN-University, Department of Mass Communication, 117198, Miklukho-Maklaya str., 6, Moscow, Russian Federation. \\ ${ }^{3}$ RSSU-University, Department of Journalism and Public Relations, 129226, Wilhelm Pieck str., 4-1, Moscow, Russian \\ Federation.
}

\begin{abstract}
The development dynamics of information and communication technologies (ICTs), especially network providing expansion of interpersonal and mass communications, radically changes the existing practice of distribution and representation of a media product. Abundant information flows in the Web form interactive competitive communication media that produce a new integrative approach to the creation of modern media models being a cumulative product of journalism, PR, marketing and advertising. An example of such model in Russian media is a branded media text which production is based on a variety of factors, both objective and subjective. Today the scientific community discusses the public adaptation of innovative media text models that could provoke comprehension of its cultural code with its possible retranslation. These parameters provide a competitive advantage and survival of any media structure. However, the conception of consumer's involvement in a media project at the stage of its creation is often an insoluble problem for journalistic department. Based on the performed studies, authors of this article, on one hand, verify the hypothesis of productivity and functionality of branded media text and, on the other hand, define the reasons for discrepancies in the approaches of leading Russian media to the use of this communicative-integration model.
\end{abstract}

\section{Introduction}

Acceleration of reformation and transformation processes is one of the leading factors in the renewal of the post-industrial world, which rapidly changes under the influence of digital technologies and intensive development of technological revolution, as well as based on the creative economy and the production of an innovative product that is original by its form and valuable by its content. These social and economic constants are fundamental for all branches of the national economy, but mostly manifested in the media industry, where transformations have covered the whole range of organizational and management relations and media products production, including the update of approaches to the formation and semantics of media text, methods of attracting the audience attention.

Social space is also changing in an accelerated rhythm: the social structure is subject to fragmentation. Social groups, layers and subcultures are actively localized, on the one hand, as well as on the other hand a so-called active media user (its number is increasing) appears in the informational space, producing its own media product, distributing it on the Internet and monetizing as well. It is a sort of the competitor to professional mass media, which, however, cannot be ignored. The expansion of communicative processes and the abundance of information flows make the person's ideas of self-identification to be reviewed, and the stereotypes for the objective world perception are changing: according to psychologists, the stereotype of "survival" existing in past gives way to the "selfexpression" stereotype (blogs, social media, social networks, messengers).

Both national and global media space is also rapidly diversifying. Its characteristic multimedia and multiplatform features are understood in the former case as the use of the complicated nature of hybrid artisticexpressive forms in the creation of an informational product, and in the latter case, as the possibility of placing such product in various media (TV broadcasting, Internet, mobile devices, social networks, gadgets, messengers, advertising platforms, video information systems (VIS) of new generation installed in the squares of the city, indoors, in auto transport, etc.). Expanding the opportunities for the distribution of media, which is original in its form, semantics and stylistics, dramatically changes the mass media content, motivating it to search for new principles of interaction with the audience, which becomes the main media market stakeholder in digital times. The competitive advantage and capitalization of media structures, as well as its survival

* Corresponding author: irma-irma@list.ru 
depend on the media user's preferences and interest in information content. All this poses many organizational and management or conceptual and creative questions to media editors, first of all in terms of improving the used media practices, among which "media business" and "customer-oriented" concepts take the first place in the production of information.

\section{Problem definition: media product commodification, focus on the client}

One of the notable tendencies in the development of the information society and the digital world in general is the intensification of commodification processes; the transformation of goods, services, ideas and people into commodities, or objects of trade), including cultural industries (commodification of culture) [1, 2].

Manifestation of commodification processes is also typical for media industries, which are included in the cultural sector. The widespread recognition of information as a commodity and service in the $21 \mathrm{st}$ century not only points to the inherent properties of the marketable product that is subject to sale, which, by the way, underscores the priority significance of "media business" term, but also generates a conflict in the professional sector regarding the goal setting of the journalistic work and "Journalism" concept in general.

Conceptual and terminological conflict is caused by the fact that throughout the history of media development, journalism as a profession has been identified with a special kind of social institution whose activities are aimed at producing and promoting new ideas and meanings that have spiritual and intellectual value and significance in the public consciousness. The main reference point here was the factor of civilizational development. Basing on this humanistic criterion, journalist's skills and mastery of the word were improved. The motivation for communicating new knowledge and information about world events in the creation of an information product was formed by the set of linguistic-phraseological methods of persuasion.

But times have changed since then. The consumer culture dominates in the consumer society. Consumerism is the norm of being, and the mass media audience is interested in the functionality of the distributed information and lexically light content, which are presented in a laconic and visual, preferably visualized form. Modern technologies give such an opportunity. Here comes the urgent need for saving free time, which is the most expensive resource in digital times. At the same time, the commercialization of media industries is intensifying, where both economic and technological vectors are at the peak of their development. All this encourages media structures to redevelop, as well as change approaches to the production of information. Professional knowledge and skills of the journalist begin to be associated with skills from other spheres of knowledge, requiring an interdisciplinary approach in the media production (creative-linguistic, economic, technological), which generally meets the requirements of the current historical era and digital media content.
The conflict of conceptual categories in professional activity forms an industrial-ideological conflict, subjecting the standards of production to be reformed. As a result, when creating media products, the pragmatics peculiar to advertising and marketing modeling comes into conflict with semantics and form (the journalistic model of the text), and the modern media text loses its organic nature, acquiring elements of context formalization. There is a new term appeared abroad that characterizes the integration of journalistic and advertising-PR approaches in media production, and ironically expressed as "churnalism" [3].

It is fair to admit that in the old days mass media activities were also included in the commodity relations (sale of newspapers, magazines, advertising on radio, TV), but this was not an obvious but intermediate nature (selling audience figures to advertisers). However, digital media space, forcing to adapt to a new medium, initiates the creation of new patterns and meta-patterns in media activities. As a result, modern media structures identify themselves more as the media business than as cultural industries, seeking to integrate advertising and marketing modeling into the journalistic and creative form of the media product, because its conceptual development is based on the idea of capitalizing the media company, which is focused on tapping new markets both on the national and global informational level. A similar strategy is set by the actively developing network media space, which, thanks to the technological platforms of the Internet and digital TV broadcasting, creates a precedent for the formation of transnational media corporations (TMCs), intended to be used all over the world, regardless of its national location. Thus, the newest historical era and civilizational progress, based on innovations of the technological revolution, predetermined the nature of the development of modern mass media in the network society, specifying the priority of economic indicators in the mass media sector.

Scientific discourse also calls for a distinction between two concepts of "media business" and "journalism". In particular, Prof. E. Vartanova suggest to have a new look at media activities, assessing creative and business processes as two components of a single whole. The author emphasizes, "The main point of journalism is the production of informational content (journalistic text) characterized simultaneously by the features of creative and industrial production", whereas "the media is the industry that provides production, packaging and distribution of all types of media texts" [4]. Thus, institutionally, the mass media is an organizational and management structure, with the production and distribution of a variety of models of media products whose quality characteristics (external and internal codes) $[5,6]$ are aimed at attracting the attention of a media consumer, influencing his socialization and providing the inflow of knowledge for the purpose of social and civilizational development. Nevertheless this definition in modern mass media reveals the nature of intra-editorial hierarchical conflict that extends to the relationship between commercial and creative divisions of the media structure, as well as the assessment of their immersion in the production process 
and the determination of responsibility for the final decision-making in the production of media products.

Theoretical grounds undoubtedly need the development of conceptual and practical methods and their testing to evaluate the productivity of an integrative approach to the production of media texts that are required by the consumer. The mass media cannot abandon the fundamental principle of its production (journalistic text), but they either cannot neglect the issues of profitability of production. The problem can be solved only experimentally, taking into account trial and error analysis, as well as analyzing statistics obtained in the modeling of hybrid media text variants. At the same time, one should also take into account the main trend, which is the development of the digital economy and the fact that the media industries can only progress in line with economic rationalism and more complex market relations. The introduction of a wide range of economic concepts and criteria (e.g. brand, brand-building, branding, customer orientation, efficiency and profitability of production, media text, etc.), focused on a pragmatic and economical approach to the production of media products, plays a significant role here. It will also be necessary to introduce methods for training in economic modeling of media products in order to adjust the ideological principles and self-consciousness of the journalist, aiming at the functional and effective action plan, whether in relation to the collection of material for a media project, or at the time of creative inspiration, when the creation, concept and form of the integration process occurs. An important aspect on the way of reforming is the formation of staff relations in the editor's office, which should start from the study and comparison of related concepts as "consideration of media user needs" and "customer-oriented approach", which can serve as a valuable addition in the work with the mass media audience. The main problem of mass media is that the target audience always remained blurred not personalized. But the digital age requires new characteristics of participants in mass communications.

\section{Hypothesis and methodology}

Identification of media structures with brands, by analogy with commercial commodity-producing companies, inevitably leads the market entity or participant to perform a number of algorithmic actions in the framework of brand-building and branding. These promotions (marketing, advertising, PR) give the company and its products the necessary image characteristics during popularization of a new product. However, do not forget about the fundamental difference between media companies and commodity producing companies, considering that the first, that is, the mass media with its line production release new products practically 24 hours a day, being so called a news driver and a news flow manager for the audience, while the second type of companies enters the information market occasionally, when it is required. Apparently, this significant discrepancy projected the appeal precisely to media text branding as the main product produced by the media company. It should also be noted that the mass media always had distinctive visualized features brand's elements and attributes (logo, design, a unique stylistics of material presentation, characterizing the corporate style), which made them recognizable to the consumer.

At the junction of journalistic product with marketing, PR and advertising, a new term - branded journalism (churnalism) appeared [3] as one of the areas of media activity. The authorization of this phrase is still in question. It is rather talking about the branded media text, which has elements of advertising and marketing innovations. This type of media production began to be published in Russia about three years ago - in 2015, having received the greatest reflection on the Internet. This was explained by a combination of typical processes of the overall plan, on the one hand, (mass media loss of the exclusive right to information from primary sources, less social interest in reading with information redundancy, nonlinear information distribution at the stage of transforming vertical unidirectional communication into a vertical horizontal model), and the evolutional development of modern advertising, which seeks to recognize cultural code in an advertising narrative in order to become a part of the culture, on the other hand $[7,8]$.

The methodology of the conducted study in the form of in-depth interviews with managers of three popular publications in Russia ("Komsomolskaya Pravda", "Argumenty i Fakty", "Russian Export Center"), which have representations on the Internet, allows us to identify not so much the fact of the editors' address to the branded media text, as much as the internal production problems associated with this type of product specify. It also allows clarifying the attitude of editors-managers to the changes, and the level of its client-orientation. The hypothesis that the categories of executives are divided into two groups is also reviewed. The propagandists who do not show sensitivity to client orientation as the basis for building communication interactions with a media consumer on the Web (lack of a marketing outlook) and represent generation formed in the conditions of informational deficit (the Soviet period); and editors-marketing specialists who possess economic knowledge and are interested in the formation of new communication models of media text. This group of media managers is distinguished by a heightened sensitivity to client-orientation (the presence of a marketing outlook), and believes that the optimal way of interacting with the consumer is dialogue, the desire to have not so boring publications, involving the audience into communication. This is what today's "digital" generation $\mathrm{Y}$, which is especially receptive to innovative forms and non-trivial content models, tends towards.

\section{Branded media text as a model of audience engagement}

All types of mass media can use the integrative approach to media texts modeling with regard to economic 
parameters, since any media structure, whether print media, Internet media or TV channel, has official representation on the Internet. Nevertheless, at this stage it is more efficient to turn to new media, whose activities are fully realized in the web.

Addressing to the Internet in terms of testing innovative models of media text is based on a number of pragmatic aspects. Modern Internet technologies are superior with regard to traditional media, it allows you to "follow the client" (targeting), programming and assessing, therefore, the journalist can count on the audience response, expressed in quantitative terms or in numbers. Assessing the audience behavior (the number of visits, the time spent on the web page with media text, etc.) allows modeling the media project for the interests of the client-media consumer. In marketing, this focus is called customer orientation, which allows identifying the necessary key performance indicators - KPIs [9]. In this case, in addition to distributing the media product to a wide audience, a journalist can identify two important criteria for KPI: the reach of the target audience and its engagement rate, reflecting the depth of interest in the media text, where the indicator is the consumer's duration on the page. However, even here there are a number of problems related to the interdisciplinarity of knowledge. First of all it is necessary to properly set up the SEO (Search Engine Optimization) of the CRMsystem of the web site in order to ensure its search optimization for the promotion of information products and the acquisition of necessary statistical data. Some marketers argue that the site itself is Internet marketing, able to identify the necessary KPIs and use them in the analysis. But this also means an improvement of the interaction between humanitarians and technical specialists, which requires dialogue and mutual understanding. In fact, this is the beginning of the understanding of the interdisciplinarity problem. Practice shows that dialogue between creators and technical experts is not always productive and effective. The areas of practical knowledge of these specialists are too far apart, and the communication skills are different. Thus, this aspect turns into a significant problem.

There is one more peculiarity when using Internet communications arousing user's interest to media products. This is the adjustment of media text on the basis of formatted features (format - a set of identification features of the product), configured for the settings and requests of the target audience. According to Jarvis, the search for information in Google (Googlethinking) provides for constant interaction with the audience, acting as an equal participant in the dialogue [10]. The journalist's attitude to the audience as an equal partner in dialogue forms the "win-win" paradigm, which is laid in the context of the form and content of the web portal, media project or media text in the form of various communication elements (comments, polls, game elements, etc.). The ready journalistic text integrated into the virtual environment should have the qualities visually presenting the author's clientorientation, which prompts the audience to a response. The media consumer promptly recognizes these qualities, even before reading the material, and quickly decides whether to follow the link or not, read or not to read, or rather, interact with media text or refuse it and switch to another media product [11].

However, in favor of modeling the media text of a hybrid-communicative form, journalism, marketing, PR and advertising realize similar conceptual tasks: all these types of communication actually sell ideas in order to find out the interest of the target audience to whether humanitarian or material products. Such pragmatic interpretation of these essentially different directions in the mass media can serve as a basis in the search for ways to construct new models of formatted media texts. In fact, the format includes not only the form and semantics of the media text presentation, but the audience's ideas about bilateral communication, so the question of the effectiveness of this communication is extremely significant. However, the rules of representation are dictated by the organic nature of the media text formation. It is necessary to determine in advance what type of creativity will be dominant in the media project and which type will be secondary. Since the dominant semantic code forms in the media text, an individualized set of artistic expressive means and communication re-translators, which influence the expectations and cognitive perception of the media user.

There are many forms of branded media text, used by the mass media on the Internet. These are longreads, which are still interesting to the consumer. Usually, verbal cognitive information dominates in it, but still infographic, video and not a light advertising promotion are integrated there. Longread manifests the interdisciplinary approach to the integration of genres and forms. There is also the format of online games, different in subject, format, provided with comments, and forms for a response to the media user. There are also special projects that are similar to longreads by its form, but differ in its content, and whose task is to provide the consumer with cognitive information, typically encyclopedic one. However, all these different media projects have a single point of reference: the customer or sponsor of the project, ready to popularize this or that socially significant idea, which finally provides the choice of the format. If the mass media does not have any sponsor, it can independently create a media project in order to increase the number of audience, as well as ensure the inflow of financial resources. This is the way to actually customize a social order for a media company, which means the production of a media project taking into account the ideas and requirements of the audience.

However, the modeling of branded media text requires the involvement of new generation of specialists who have interdisciplinary knowledge and skills. One of the main figures in work with Internet communications becomes a transaction editor (from Latin translation agreement, contract), who possesses not only the skills of preparing journalistic text and direct marketing techniques, but also can conduct a transactional analysis of the audience according to Eric Berne theory [12] in order to identify the psychological motives for its behavior, identify the main preferences of media users and, in addition, understand the functioning of the SEO 
and CRM-system of the web site. Such multidimensionality of knowledge and skills can be formed only with an interdisciplinary approach [13].

\section{Results of the study: analysis of in- depth interviews}

\subsection{Reasons for interest in new integration media models}

Generally, interviews with managers of several Russian media revealed a number of trends in terms of adapting models of branded media text, attitude to this type of media production. An important indicator was that, due to a noticeable decline in the interest of the audience to modular advertising, advertisers became interested in the so-called "native advertising", which has the format of "natural" advertising, not causing any rejection or cognitive dissonance from the consumer. The reorientation of the advertiser to another format of commodity representation served as a point to increase the demand for branded media text, the volume of which has increased threefold since 2015 in Internet media sites, however, leading to a reduction in the positioning of editorial texts (the web portal of "Argumenty i Fakty", www.aif.ru). The growth of branded media text in the web is recognized by the editors of "Komsomolskaya Pravda" (www.km.ru), "Russian Export Center" (www.exportcenter.ru/press_center/magazins/), new edition for Russian export-oriented entrepreneurs.

\subsection{Columns and location}

The interview also clarified that, despite the complexities of designing a branded media text that requires the consolidation and mutual understanding of journalists, advertisers and marketers, this type of media product is more often and carefully branded in the columns related to the positioning of industrial goods. For example, in such headings as "Economy", "Real Estate", "Auto", "Health". This is based on the task facing the editors when using the format of branded media text, where cognitive information is published under a certain brand, including the logo of the customer company, and goes with a picture of the product package. Media companies do not hide the sponsor's participation in the branded media project, openly presenting this fact (www.km.ru). Such transparency allows drawing following conclusions: the main initiator in the promotion of hybrid forms of media products, as well as the customer or sponsor are commodity-producing companies sensitive to the needs of consumers and interested in promoting their products.

\subsection{Formats and forms}

During the interview, various forms and formats of using branded media text were discussed in detail. Finally, it was confirmed that the most popular media projects of this type are longreads in various forms, combining a journalistic text and visualized advertising elements, infographics, video; various formats of online games, put into exciting advertising and educational form; specialized projects of cognitive nature, ranging from one to three or more pages of representation, often devoted to socially important topics or the presentation of various kinds of cognitive information, for example, a historical and geographical plan with maps, guides, sightseeing and other materials. The use of business-case models is also in practice. It usually presents a story about one of the directions of a commodity-producing company, supplemented by quotations of the general director. It was also clarified that the less popular model among advertisers is an interview, since modern media users do not like this genre, especially if the expert advertising goods is not so popular among the audience.

\subsection{Audience perception}

The choice of the format for the creation of a branded media project is primarily driven by the idea that the customer intends to popularize, as well as the volume of providing useful information in the web. But anyhow, the main goal of such media product is projected to awaken consumer's interest in the media text, reduce "pressure" on the perception of advertising elements and forms by the audience. It was also important that sponsors are interested in implementing such media projects, and there are many commercial proposals. It is also interesting to note that the audience reaction to such special projects is quite positive. For example, the popularization of the idea "What is the best New Year present for your relatives?" brought nearly 50,000 responses and references to the web portal of "Komsomolskaya Pravda" (www.kp.ru), significantly increasing the traffic of both the advertiser and the media company. Such advertising-oriented branded media projects, according to all interviews, help media companies to survive.

\subsection{The problem of a conflict}

The interview involves the topic of interaction between commercial and creative divisions of the media editorial staff during branded media text preparation. The main collision here is built on the fact that many journalists "turn away" from advertising materials, are ashamed of them, and this mental rejection creates a collapse in the preparation of new media products. However, not only this aspect prevails in this case, but also the fact that during creating a branded media text the journalist should understand the advertising concept of the new project and think as a marketer, master the logic of material formation and have the skills to work with a photo-editor, designer and programmer as well. In this respect, it is especially difficult for older journalists who are focused on the social importance of the published materials on the one hand and on the other hand do not have prognostic marketing knowledge, do not have the skill to format materials on the web portal. The difference in approaches and knowledge is manifested in 
the work of journalists with both advertisers and representatives of commercial divisions of the media company.

\subsection{Disadvantages and its reasons}

As a result, the issues of finding interdisciplinary knowledge and skills in forecasting the demand for branded media text both from the point of its social importance and in terms of analyzing economic indicators come to the forefront. The lack of a marketing outlook, knowledge from interdisciplinary areas leads to alterations of the branded media project, proving its low profitability. As noted in the interview, a serious shortcoming in the work on creating more complex communicative-integrative models of media text is, first of all, the lack of understanding of interdisciplinary links that are in demand and motivate to attract ideas from related fields of knowledge, allowing to find new semantic "twists" for media text and its content. In addition, a serious lacuna is the undeveloped communication methods in a teamwork format, eventually affecting the organic and emotional susceptibility of the media product.

\subsection{Results of the interview}

Summing up the in-depth interviews, we can state: representatives of the interviewed Russian mass media agreed that the boundaries between journalism and advertising will be erased more actively, as new communicative and integrative models of branded media text provide modern media with the flow of funds and interaction with advertisers. However, this direction of the media industry is still at the initial stage of its development and will continue to progress in the future. At this stage, the mass media distribution of this type of media products is of great importance in terms of promoting branded media text, while understanding the quality of the audience has not yet been realized. The interest shown to the branded media text by most important persons in the society makes it possible to create a precedent for its long-term promotion, and this value is indisputable.

\section{General Conclusions}

The results of the performed study first of all indicate the scale and heterogeneity of the ongoing transformation processes in the media industry at the stage of digitalization that develop vertically and horizontally, forcing media companies to reorganize on the run. It becomes obvious that in this information society, media structures cannot use outdated concepts and management techniques taken from the industrial era. This imbalance is manifested primarily in the professional production activity of the mass media, closely related to the media economy. In this regard, the survival of media companies is becoming paramount.

The new conditions of the modifying media space dictate the updating of criteria and principles of media activity, where the factor of the success and prosperity of the media is the release of the original in form and unique in the semantics media product capable of activating the audience attention, involving the media user in information flows. The emergence and testing of new communication and integration models in the form of branded media texts proves this fact. However, further promotion of media companies along the reform path requires diagnosing the core areas of the media industry, identifying the cost criteria for creating a media product, as well as assessing the importance of creative and intellectual investments in social development. The practice of interaction with advertisers, who initiated the creation of branded media projects, confirms the possibility of promoting the mass media along the path of economic development.

The attitude towards journalism, which was formerly treated as a strictly philological profession, and now acquires the features of a media business, where an interdisciplinary approach to the production of media products prevails, also undergoes the correction. This requires both technological and economic knowledge from journalists, as marketing and client-oriented approaches begin to prevail in media production. Analysis of the use of branded media texts in the web shows that the communication-client-oriented (marketing) approach, which is still adjacent to the propagandistic (egocentric, mediacentric) approach used in the industrial era, starts to be developed in editorial policy. But this practice will be gradually reduced, as, the economic factor will be dominant in the digital economy and among increasing competition in the national and global information space.

The need for professionals of a new generation, for example, a transaction editor with interdisciplinary knowledge and skills, capable of identifying an algorithm of active interaction with the audience, becomes a significant task. In order to accelerate the reformation of media companies, it is necessary to test the university's training programs for journalists, supplementing them with relevant disciplines that reveal the importance of marketing thinking in the realities of modern media production. The study confirms that the media operate in fundamentally new conditions in the digital age, thus increasing the requirements for organizational and managerial methods and the level of professional knowledge, competencies and skills. Problem-based learning [14] and the systematic interdisciplinary approach to the issues of reformation and media education will allow the media industry to enter the path of successful competition in the national and global media market.

Time for mastering new interdisciplinary knowledge still exists, but it is marginal. According to Gartner's research and consulting company, specializing in information technology markets, $85 \%$ of communications between companies and consumers will be implemented using artificial intelligence by 2020 [15]. And although it is hard to predict a successful adaptation of artificial intelligence on the Russian media market, it is still necessary to consider this trend of technological development. Software products related to 
artificial intelligence, in principle, open incredible opportunities for marketing communications that can quickly study not only the individual needs of the consumer, but also analyze the effectiveness of the media product. It seems that the algorithm of artificial intelligence introduced into marketing will allow modeling many different communicative and integration models of branded media text, where journalistic text and advertising elements will meet harmony and synergy.

All the authors contributed equally to the writing of this paper. The authors read and approved the final manuscript. The authors declare that they have no competing interests.

\section{References}

1. G. Murdock, International Journal of Communication 7, 154-172 (2013)

2. D. Hesmondhalgh, The Cultural Industries (Sage Publications, Thousand Oaks, 2007)

3. D. Jackson, K.Moloney, Journalism Studies $\mathbf{1 7 . 6}$ (2015)

4. E. Vartanova, Mediascope 1 (2010)

5. N. Luhmann, Die Realitat der Massenmedien (GWV Fachverlage Gmbh, Wiesbaden, 2004)

6. S. Urazova, Vestnik VGIK 5, 114-122 (2010)

7. C. Rapaille, The Culture Code: An Ingenious Way to Understand Why People Around the World Live and Buy as They Do (Crown Business, New York, 2007)

8. O. Gasparian, The World of the Russian Word 1, 56-61, (2016)

9. M. Badawy, et al, Future Computing and Informatics Journal 1.1-2, 47-53 (2016)

10. J. Jarvis, Negotiating for News: The Principles at Stake with Facebook, et al, Medium URL: https://themedia.center/2015/07/22/peregovoryi-onovostyah/ (date of access: 28.03.18).

11. I. Volkova, D. Guzhviy, RUDN Journal of Studies in Literature and Journalism 22.3, 532-543 (2017)

12. E. Berne, Games People Play: The Basic Handbook of Transactional Analysis (Ballantine Books, New York, 1964)

13. S. Bell, The Clearing House 83.2, 39-43 (2010)

14. A. Walker, et al, Overview of Problem-based Learning: Definitions and Distinctions (Purdue University Press, 2015)

15. M. Stulov, New Marketing: How Does Artificial Intelligence Change Relationships With Consumers? Vedomosty. 02.03.2018. URL: https:// www.vedomosti.ru/partner/articles/2018/03/02/7525 51-ot-redaktsii\# (date of access: 23.03.18) 